\title{
А. А. Мокрушина
}

\section{ОСОБЕННОСТИ СОВРЕМЕННОЙ АРАБСКОЙ ЛИТЕРАТУРЫ НА ПРИМЕРЕ ТВОРЧЕСТВА МОЛОДЫХ АРАБСКИХ ПРОЗАИКОВ}

\author{
Санкт-Петербургский государственный университет, Россия, 199034, Санкт-Петербург, \\ Университетская наб., 7-9
}

Статья посвящена особенностям современной арабской литературы на примере творчества молодых прозаиков. Арабская современная литература все еще остается недостаточно изученной сферой как в отечественной, так и в европейской арабистике. Молодые писатели во всем мире сталкиваются с общей проблемой: им сложно найти выход к читателю. Арабскую литературу, которую отличает особая приверженность традиционным жанрам и приемам, можно назвать консервативной. Однако сегодня внимание молодых арабских авторов привлекают жанры, уже давно полюбившиеся их европейским коллегам. Тематика, которую выбирают молодые арабские писатели, разнообразна, начиная с бытовых сюжетов и заканчивая размышлениями на политические и философские темы. Одно из главных мест в творчестве арабских писателей продолжает занимать тема борьбы. При этом авторы редко ограничиваются одной сюжетной линией в своем повествовании. В настоящий момент общие тенденции современной арабской литературы во многом совпадают с тенденциями мировой литературы, сохраняя при этом целый ряд специфических черт. Библиогр. 16 назв. Ил. 14.

Ключевые слова: современная арабская литература, молодые писатели, проза, арабский рассказ, арабский роман.

\section{MODERN ARABIC LITERATURE: LITERARY WORKS OF YOUNG NOVELISTS}

\section{A. A. Mokrushina \\ St Petersburg State University, 7-9 Universitetskaya nab., St. Petersburg, 199034 Russian Federation}

The article is devoted to the modern Arabic literature based on the literary works of young novelists. Modern Arabic literature still remains understudied area, both in Russia and in Europe. Young writers around the world are faced with a common problem: it is difficult to find a means to reach the reader. Arabic literature may be called conservative. Today, however, young Arab authors are interested in the genres which their European colleagues were interested in several decades ago. Nowadays modern Arab novelists choose different themes for their literary works - there are everyday life topics as well as political and philosophical themes. The theme of struggle is one of the most important in the works of Arab writers. The authors are rarely confined to a single storyline in his narrative. The general trends of modern Arabic literature largely coincide with the trends of world literature with a number of specific features. Refs 16. Figs 14.

Keywords: modern Arabic literature, young novelists, prose, Arabic novel.

Арабская современная литература все еще остается недостаточно изученной областью как в отечественной, так и в европейской арабистике. Несмотря на то что эта тема в последние годы вновь привлекает внимание исследователей, существует весьма ограниченное количество научных работ, посвященных анализу творчества арабских писателей и поэтов, создававших свои произведения с 1970-х годов. Что касается работ молодых арабских писателей, то с ними зачастую недостаточно знакомы даже специалисты.

Следует отметить, что молодые писатели во всем мире сталкиваются с общей проблемой: им сложно найти выход к читателю. Издательства, как крупные,

(c) Санкт-Петербургский государственный университет, 2017 
так и мелкие, предпочитают публиковать произведения известных авторов, давно ставшие классикой. Лишь немногие издатели идут на риск, публикуя работы молодых писателей. Как правило, подобные шаги редко окупаются: читающая аудитория также неохотно реагирует на новые имена в литературе. Таким образом, перед издателями встает новая задача - необходимость финансировать рекламу, чтобы обеспечить продажи. Все это редко находит отклик у издательств, нацеленных на гарантированное получение дохода с минимальными вложениями со своей стороны.

Молодые писатели, еще не известные широкой публике, обычно получают возможность бумажной публикации благодаря различным фондам. В арабском мире также учреждены премии для поддержки молодых прозаиков, пишущих на арабском языке. Большинство подобных изданий выходит в Ливане, Египте и Кувейте.

Разумеется, далеко не все начинающие авторы имеют возможность получить спонсорскую поддержку для публикации. Для знакомства читателей со своим творчеством они используют самый простой и доступный способ - Интернет. Арабские молодые писатели в этом смысле не исключение. Бо́льшую часть их работ можно найти в свободном доступе в Интернет-сети.

Тематика, которую выбирают современные арабские авторы для своих произведений, разнообразна, начиная с бытовых сюжетов и заканчивая политическими и философскими темами.

Короткий рассказ молодого ливийского прозаика Фатхи Насиба / فتحي نصيب названием «Новое утро» / الصباح الجديد - небольшая зарисовка из жизни писателя. Совершенно очевидно, что автор отождествляет себя с героем рассказа: с грустной иронией он пишет, что никак не может выправить свой последний рассказ, «проклиная учителя арабского языка, который узрел в моих чертах будущее дарованье» [1]. Структура рассказа напоминает заметки в дневнике, которые делает для себя герой. Кроме того, после текста рассказа следуют примечания, поясняющие положение дел в семье главного героя и носящие юмористический характер. Например, автор пишет, что они с женой планируют совместный ужин с друзьями, а затем в примечаниях дает следующий комментарий: «Уидад и ее муженек - самая скучная супружеская пара на земле! Однако моей жене они нравятся. Наверное, потому что Уидад безобразна. А моя жена никогда не позволит войти в наш дом красивой женщине» [1].

Совершенно иной по содержанию и форме изложения короткий рассказ Мухаммада Ибрахима Махруса / محمد إبر اهيم محروس "Автобус» [2]. Писатель родился

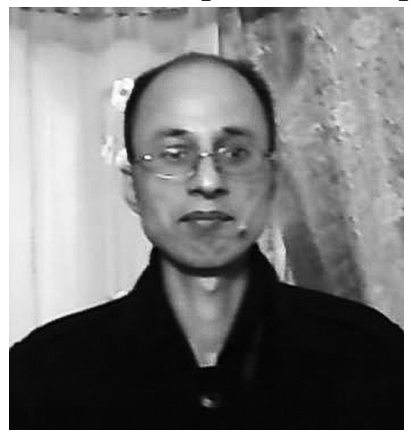

Рис. 1. Мухаммад Ибрахим Maxpyc [3] в 1973 г. в г. Исмаилийя (Египет) и начал литературную деятельность в 2000 г., в 2005 г. было опубликовано его первое произведение. В коротком рассказе «Автобус» / перед читателем предстает история жизни простого служащего - кондуктора автобуса. Человека, который тридцать лет выполнял свою работу, становясь свидетелем не только человеческих судеб, но и изменений в масштабах страны и даже всего мира. Герой рассказа вспоминает о том, как он вместе со всеми выходил на улицы родного города во время акций протеста, как пережил кризис в стране, как размышлял, кто на самом деле руководит действиями бен Ладена. 
Перед глазами этого человека - миллионы лиц пассажиров, которых он ежедневно видел в автобусе номер 6 [2].

Другой рассказ Мухаммада Ибрахима Махруса под названием «Возраст осени» / عر الخريف повествует об истории любви пятидесятилетнего мужчины к двадцатипятилетней девушке - coтруднице его отдела. Внезапное чувство, охватившее главного героя, вызывает у него грусть и смятение. И хотя девушка отвечает ему взаимностью, главный герой не перестает задавать себе один и тот же вопрос: может ли быть чтото общее у человека в возрасте осени и молодой девушки в возрасте весны? [3].

Мухаммад Ибрахим Махрус - автор нескольких опубликованных романов. Самый известный роман этого писателя - «Азиз» / عزيز рассказывает не о человеке, как можно было бы предположить по названию, а об улице, наполненной своей атмосферой и тайнами. Герой романа пытается понять самого себя через события, происходящие на улице Азиз [4].

Египетский прозаик Ибрахим Фаргали / - إبر اهيم فرغالي автор коротких рассказов и нескольких романов. Писатель родился в 1967 г. в г. Мансура (Египет), где окончил университет. В настоящий момент Ибрахим Фаргали работает журналистом в издании «ал-Араби» в Кувейте. В 2012 г. он был награжден египетской литературной премией для молодых писателей.

Произведение Фаргали «Святилище шелковых пальцев» / معبد أناميل الحرير - это роман-фантазия, в котором переплетаются три различные сюжетные линии. В этой истории фигурирует загадочная рукопись, ее автор и даже пираты. В романе молодого прозаика ощущается влияние современной европейской литературы: броское привлекающее внимание название, захватывающий сюжет, легкий слог [5].

Ахмад Саадауи / أحمد سعداوي, молодой иракский прозаик, поэт и сценарист, родился в 1973 г. Автор сборника стихов, а также трех романов «Красивая страна» (2004 г.), «На самом деле он мечтает, молится или умирает» (2008 г.) и «Франкенштейн в Багдаде» (2013 г.). Ахмад Саадауи не-

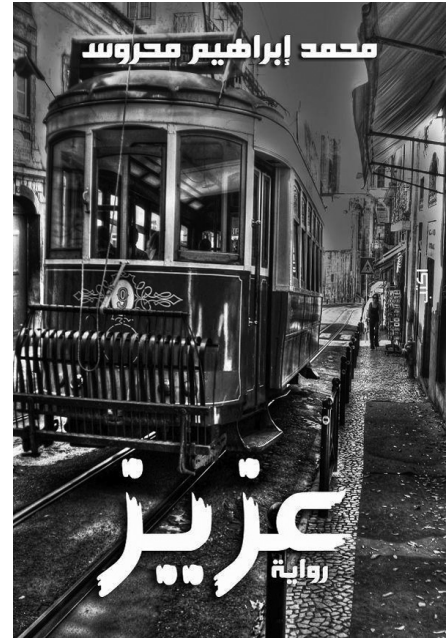

Puc. 2. Обложка романа «Азиз» [3]

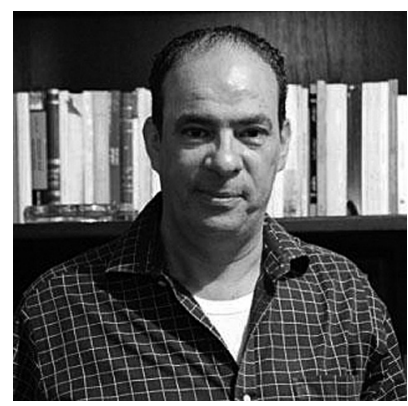

Рис. 3. Ибрахим Фаргали [6]

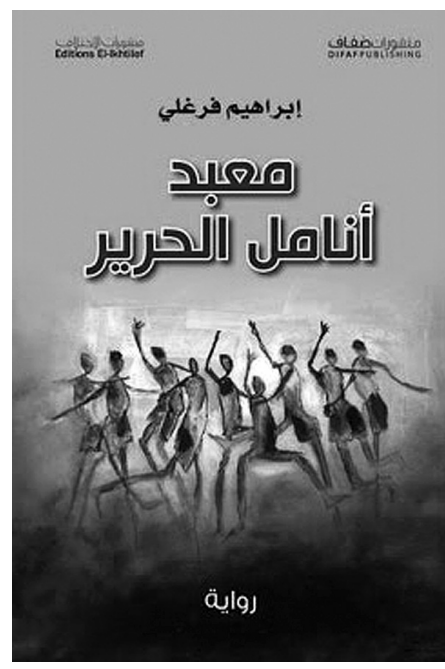

Рuc. 4. Обложка романа «Святилище шелковых пальцев» [5] 


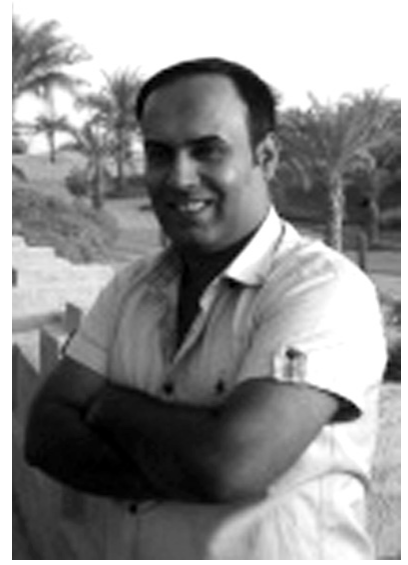

Рuc. 5. Ахмад Саадауи [7]

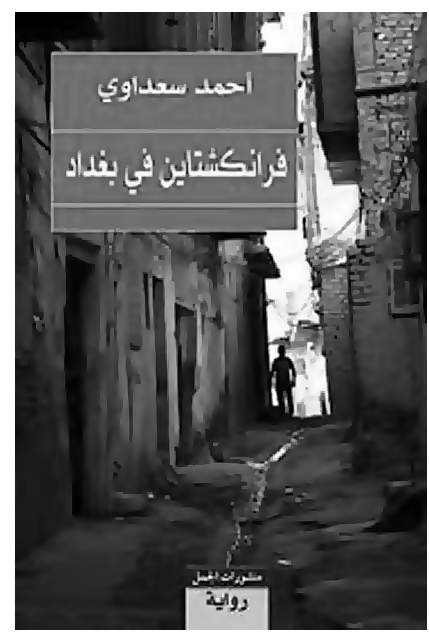

Рис. 6. Обложка романа «Франкенштейн в Багдаде» [8]

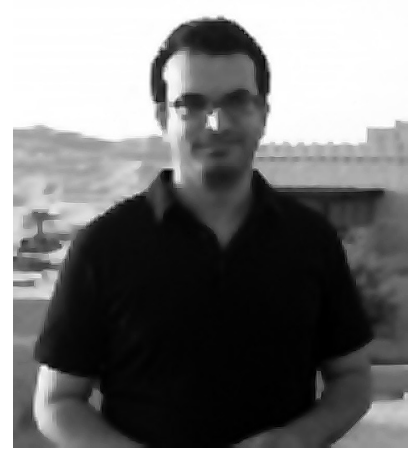

Puc. 7. Мухаммад Рабии [9] однократно награждался различными литературными премиями для молодых писателей [7].

Сюжет романа «Франкенштейн в Багдаде» / во многом повторяет сюжетную линию романа Мэри Шелли. Один из главных героев романа живет в Багдаде 2005 г. После серии взрывов, произошедших в городе, он собирает останки погибших и создает новое существо, которое, в свою очередь, начинает поиски тех, кто был повинен в смерти людей, погибших от взрывов. Автор рисует картину багдадского общества, где люди живут в страхе перед неизвестностью и не имеют возможности сплотиться для борьбы с преступником [8].

Мухаммад Рабии / محمد ربيع родился в 1978 г., получил образование инженера в Каирском университете. Автор нескольких романов, два из которых были отмечены литературными премиями для молодых писателей [9].

Последний роман прозаика носит название «Меркурий» / عطارد. Произведение представляет собой яркий пример антиутопии. События альтернативным образом разворачиваются в Египте после январской революции 2011 г. Главный герой романа, полицейский, становится свидетелем страшных перемен в стране, приведших к беспределу, убийствам и грабежам. Народное сопротивление сражается с непонятными мистическими силами, стремящимися посеять в стране еще больший хаос [10].

Молодая писательница из Сирии Шахля алУджайли / شهلا العجيلي родилась в 1976 г. Она защитила диссертацию в Университете Алеппо по современной арабской литературе и в настоящее время преподает арабскую литературу в одном из университетов Иордании. Шахля ал-Уджайли - автор сборника рассказов «ал-Машрабийа», который был опубликован в 2005 г., а также нескольких романов: «Кошачий глаз», «Персидский ковер» и «Небеса вблизи нашего дома». Шахля ал-Уджайли также автор ряда рецензий [11].

Произведение писательницы «Небеса вблизи нашего дома» / سماء قريبة من بيتنا - это исторический роман, охватывающий период со второй половины XIX в. до наших дней. Весь сюжет разворачивается в столице Иордании Аммане. Автор знакомит читателя с персонажами - представителями разных слоев общества Аммана. Главный герой, сириец- 
эмигрант, знакомится здесь с палестинцем сирийского происхождения, приехавшим в Амман на похороны матери. Вскоре они выясняют, что их деды дружили когда-то, но войны развели друзей и их семьи по разным уголкам мира. Основная мысль всего романа очевидна: автор подчеркивает, что глобальные беды, связанные с войнами, не могут перекрыть страдания отдельных людей [12].

Молодой арабский писатель из Судана Хамид ан-Назир / حامد الناظر родился в 1975 г. Он штатный журналист нескольких печатных изданий, а также интернет-изданий. Первый роман молодого автора, вышедший в 2014 г., был отмечен сразу двумя литературными премиями [13].

Второй опубликованный роман Хамида анНазира носит название «Пророчество торговца напитками» / نبوءة السقا. Его события происходят в 1960-х годах. Главная сюжетная линия произведения - борьба Эритреи за независимость от Эфиопии. В романе также присутствует любовная линия [14].

Писатель их Ирака Хазим Камаль ад-Дин / старше уже упомянутых авторов. Он родился в 1954 г. Хазим Камаль ад-Дин не только автор рассказов и романов, он также занимается научной работой, читает лекции в европейских университетах. Долгое время он занимал должность директора театра «Сахара 93» [15].

Писатель недавно представил публике свой новый роман под названием «Опустыненные воды» / مياه منصخرة. Автор пытается сразу заинтриговать читателя: используя свое настоящее имя, он ведет повествование от первого лица так, что у читателя складывается впечатление, будто речь идет о самом авторе книги. Но героя романа внезапно убивают. Герой Камаль ад-Дина - известный режиссер, забытый после смерти. «Опустыненные воды» - это название фильма, который он снял. Фильм был отмечен самой престижной наградой в стране - премией имени Саддама Хусейна, но суть в том, что фильм, критикующий режим Саддама, был настолько сильно подвергнут цензуре, что его смысл полностью изменился. Сюжетная линия романа крутится вокруг тайны убийства режиссера [16].

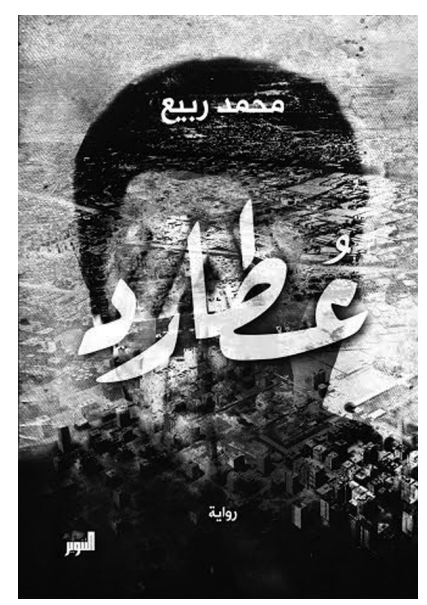

Рuс. 8. Обложка романа «Меркурий» [10]

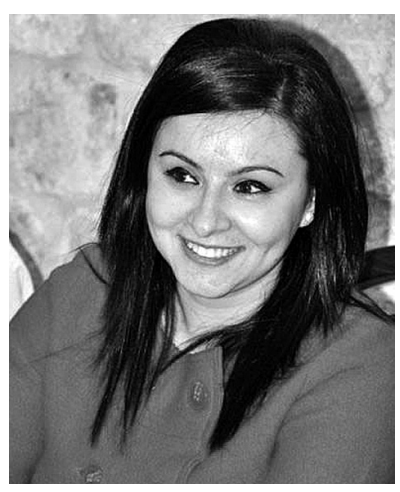

Puc. 9. Шахля ал-Уджайли [11]

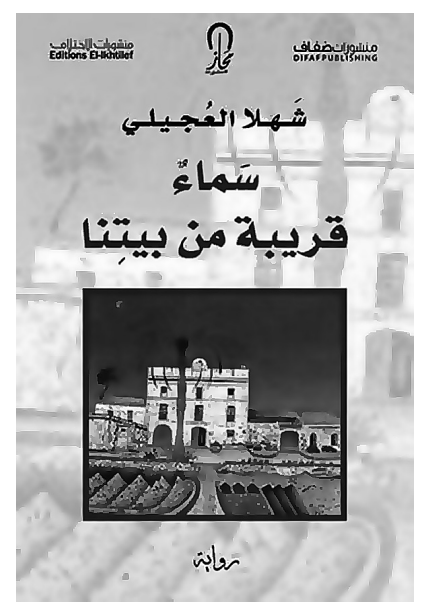

Рuc. 10. Обложка романа «Небеса вблизи нашего дома» [12] 


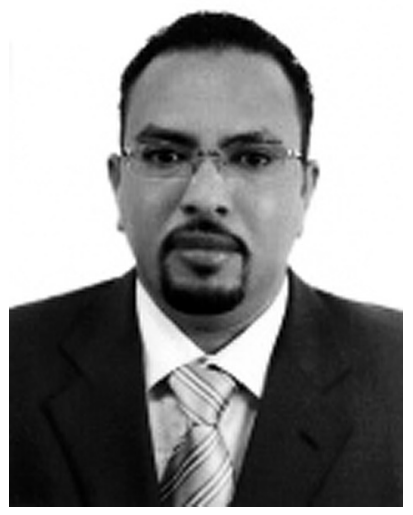

Рuс. 11. Хамид ан-Назир [13]

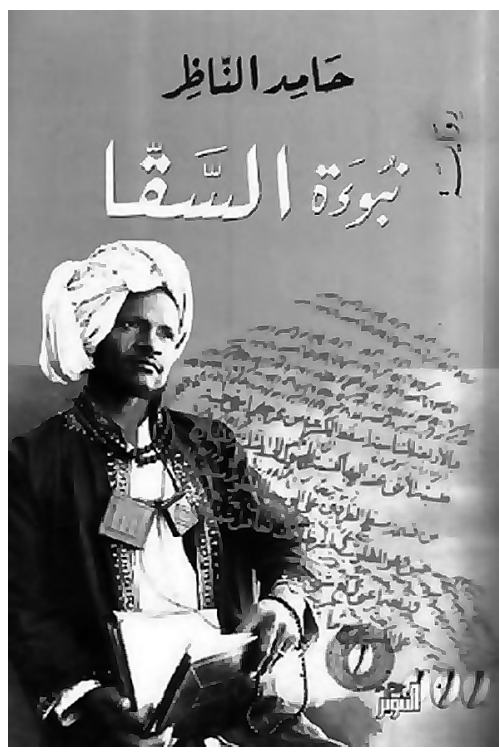

Рuc. 12. Обложка романа

«Пророчество торговца напитками» [14]

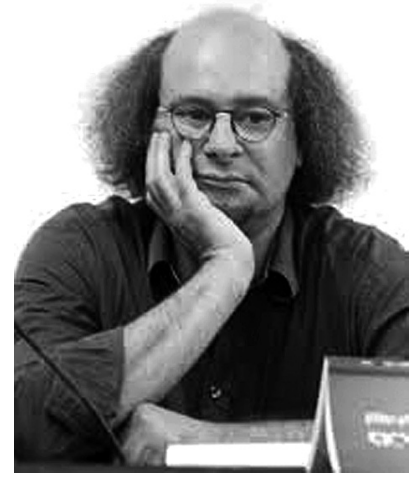

Рuc. 13. Хазим Камаль ад-Дин [15]

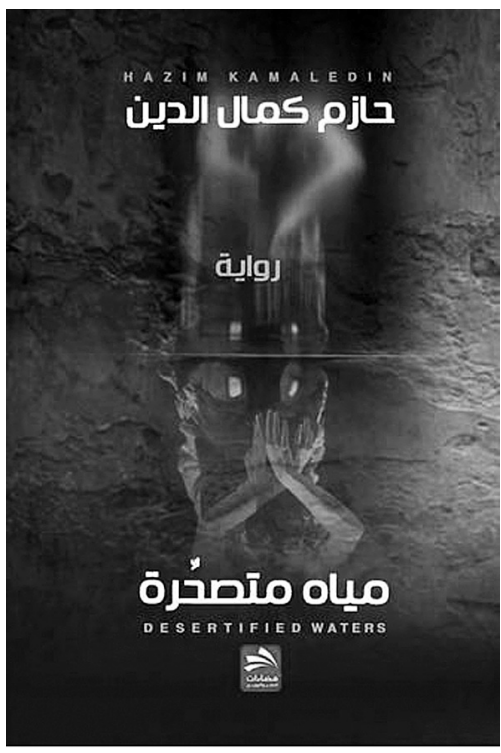

Рuc. 14. Обложка романа «Опустыненные воды» [16]

Подводя итог, можно сказать, что внимание молодых арабских авторов привлекают жанры, уже давно полюбившиеся их европейским коллегам. Так, исторический роман, известный арабскому читателю уже несколько веков, обретает новые формы. Жанр романа-антиутопии нельзя считать классическим для арабской современной литературы, но и он постепенно появляется в «репертуаре» современных арабских писателей. Одно из главных мест в творчестве молодых арабских писателей продолжает занимать тема борьбы, будь то борьба за независимость или борьба с потусторонними силами. При этом авторы редко ограничиваются в своем повествовании одной сюжетной линией, что было свойственно арабской литературе всего несколько десятилетий назад. Следует также отметить, что большинство изученных произведений написаны легким слогом, без присущего классической 
арабской литературе украшения речи за счет сложных оборотов и сравнений. Все это, очевидно, направлено на то, чтобы заинтересовать арабского читателя, искушенного чтением европейских романов. Таким образом, общие тенденции современной арабской литературы во многом совпадают с тенденциями мировой литературы, сохраняя при этом некоторые специфические черты - в основном в выборе места действия и языковом выражении.

\section{References}

1. Available at: http://www.arabworldbooks.com/authors/fathi_nasib.htm (accessed: 6.04.2016).

2. Available at: http://m.ahewar.org/s.asp?aid $=128169 \& \mathrm{r}=25 \& \mathrm{cid}=0 \& \mathrm{u}=\& \mathrm{i}=3106 \& \mathrm{q}=$ (accessed: 31.03.2016).

3. Available at: http://maspiro.net/culture/12903-2014-05-16-00-31-11.html (accessed: 27.03.2016).

4. Available at: http://www.goodreads.com/book/show/20518758 (accessed: 10.03.2016).

5. Available at: http://ketab4pdf.blogspot.ru/2016/03/pdf-Download-novel-Temple-fingertips-silkIbrahim-Farghali.html (accessed: 27.12.2015).

6. Available at: http://www.arabicfiction.org/book/137.html (accessed: 17.03.2016).

7. Available at: http://www.arabicfiction.org/author/87.html (accessed: 17.03.2016).

8. Available at: http://booksqarabic.blogspot.ru/2015/10/bagdad.html (accessed: 29.11.2015).

9. Available at: http://www.arabicfiction.org/book/146.html (accessed: 17.03.2016).

10. Available at: http://ketab4pdf.blogspot.ru/2016/02/pdf-Download-novel-Mercury-bookMohamed-Rabie.html (accessed: 3.12.2015).

11. Available at: http://www.arabicfiction.org/author/131.html (accessed: 17.03.2016).

12. Available at: http://www.goodreads.com/book/show/27427019 (accessed: 12.01.2016).

13. Available at: http://arabicfiction.org/author/158.html (accessed: 17.03.2016).

14. Available at: http://www.books4arab.com/2016/04/pdf_263.html (accessed: 22.01.2016).

15. Available at: http://arabicfiction.org/author/155.html (accessed: 17.03.2016).

16. Available at: http://www.alhaya.ps/pdf/2015/7/13/page11.pdf (accessed: 8.02.2016).

Для цитирования: Мокрушина А. А. Особенности современной арабской литературы на примере творчества молодых арабских прозаиков // Вестник СПбГУ. Востоковедение и африканистика. 2017. Т. 9. Вып. 1. С. 51-57. DOI: 10.21638/11701/spbu13.2017.105.

For citation: Mokrushina A.A. Modern Arabic literature: literary works of young novelists. Vestnik SPbSU. Asian and African Studies, 2017, vol. 9, issue 1, pp. 51-57. DOI: 10.21638/11701/spbu13.2017.105.

Статья поступила в редакцию 17 сентября 2016 г. Статья рекомендована в печать 24 ноября 2016 г.

Контактная информация

Мокрушина Амалия Анатольевна — кандидат филологических наук; kodzik@inbox.ru Mokrushina Amalia A. _ PhD; kodzik@inbox.ru 